\title{
Pengelolaan Penerimaan Peserta Didik Baru (PPDB) Berdasarkan Sistem Zonasi di SMP Negeri 1 Mlonggo Jepara
}

\author{
Sheila Rohmah*, Wahyudi, Fanzal Pamungkas
}

Universitas Islam Negeri Walisongo, Semarang, Indonesia

\begin{abstract}
ABSTRAK
Penelitian ini dilatarbelakangi oleh adanya kesulitan calon peserta didik baru untuk mendaftar sekolah di beberapa SMP Mlonggo Jepara. Salah satu sekolah yang sudah menerapkan PPDB online adalah SMP Negeri 1 Mlonggo Jepara. Keunggulan SMP Negeri 1 Mlonggo Jepara diantaranya adanya minat yang tinggi dari calon peserta didik, sarana dan prasarana lengkap dan memadai, tim IT yang proesional, letak sekolah strategis sehingga mudah dijangkau oleh transportasi umum. Penelitian ini bertujuan mendeskripsikan pengelolaan PPDB berdasarkan sistem zonasi yang meliputi: 1) perencanaan, 2) pengorganisasian, 3) pelaksanaan, 4) pengawasan. Penelitian ini adalah penelitian kualitatif dengan menggunakan metode pengumpulan data melalui wawancara, observasi, dan dokumentasi. Informan terdiri dari kepala sekolah, ketua panitia PPDB, dan peserta didik baru. Hasil yang diperoleh dalam penelitian ini adalah: 1) perencanaan kegiatan PPDB dilakukan sesuai juknis dari pemerintah, 2) pengorganisasian PPDB dilakukan pasca pembentukan panitia PPDB dan panitia PPDB dipilih berdasarkan pendidik dan tenaga pendidik yang mengusai ICT, 3) pelaksanaan PPDB dilakukan secara online mandiri dan offline, 4) pengawasan PPDB dilakukan kepala sekolah dan panitia PPDB. Kesimpulan dari penelitian ini adalah pengelolaan PPDB dilaksanakan sesuai dengan juknis dari pemerintah, pendaftaran dilakukan secara online dan offline serta memberikan pelayanan yang prima kepada masyarakat.
\end{abstract}

Kata kunci: pengelolaan; PPDB; sistem zonasi

\begin{abstract}
This research is motivated by the difficulty of prospective new students to enroll in several SMP MIonggo Jepara. One of the schools that has implemented PPDB online is SMP Negeri 1 Mlonggo. The advantages of SMP Negeri 1 Mlonggo Jepara includes high interest rom prospective students, complete and adequate facilities and infrastructure, a proessional IT team, strategic school location so that it is easily accessible by public transportation. This study aims to describe the management of PPDB based on a zoning system which includes: 1) planning, 2) organizing, 3) implementation, 4) supervision. This research is a qualitative research using data collection methods through interviews, observation and documentation. The informants consisted of the school principal, the head of the PPDB committee, and new students. The results obtained in this study are: 1) Planning for PPDB activities is carried out according to technical guidelines from the government, 2) Organizing is carried out after the formation of the PPDB committee and the selection of the PPDB committee based on educators and teaching staff who master ICT, 3) implementation of new student registration is carried out online and offline, 4) PPDB supervision is carried out by the principal and the PPDB committee. The conclusion of this research is that the management of PPDB is carried out as accordance with technical guidelines from the government, registration is done online and offline, and provide excellent service to the community.
\end{abstract}

Keywords: management; PPDB; zoning system

\section{PENDAHULUAN}

Pendidikan merupakan sarana untuk menumbuhkan dan mengembangkan bakat serta kemauan manusia agar mampu berkembang dengan optimal. Pendidikan mempunyai peran penting dalam mencerdaskan dan memajukan kehidupan bangsa. Adanya pendidikan diharapkan mampu memperbaiki kondisi masyarakat yang majemuk mulai dari tingkat atas, menengah maupun yang paling bawah.

\footnotetext{
* Corresponding Author.

Email address. sheilarahma27@gmail.com (S. Rohmah)
} 
Setiap warga negara Indonesia berhak untuk memperoleh pendidikan. Pendidikan bertujuan untuk mengubah kehidupan manusia ke arah yang lebih baik, mengembangkan kepercayaan diri sendiri, mengembangkan rasa ingin tahu, serta meningkatkan pengetahuan dan keterampilan yang telah dimilikinya. ${ }^{1}$

UU No. 20 tahun 2003 tentang Sistem Pendidikan Nasional (Sisdiknas) menyatakan bahwa pendidikan adalah usaha sadar dan terencana untuk mewujudkan suasana belajar dan proses pembelajaran agar peserta didik secara aktif mengembangkan potensi dirinya untuk memiliki kekuatan spiritual keagamaan, pengendalian diri, kepribadian, kecerdasan, akhlak mulia, serta keterampilan yang diperlukan dirinya, masyarakat, bangsa, dan negara. ${ }^{2}$

Sekolah merupakan lembaga pendidikan yang mengelola dan mengatur peserta didik untuk mengembangkan bakat dan minat yang dimiliki, kemudian diarahkan dan didorong agar mencapai tujuan yang diinginkan. Tahapan awal untuk memulai jenjang pendidikan formal yaitu tahap Penerimaan Peserta Didik (PPDB). PPDB adalah proses penarikan calon peserta didik untuk dijadikan input sekolah. Kegiatan ini rutin dilakukan sekolah setiap tahun ajaran baru. Tahap PPDB harus dikelola dan dilaksanakan sesuai standar yang telah ditetapkan pemerintah.

Pada tahap PPDB, selama ini masyarakat sudah terbiasa menggunakan nilai ujian nasional atau melalui tes yang diselenggarakan pihak sekolah sebagai bahan pertimbangan agar diterima di suatu sekolah yang diinginkan. Lambat laun hal tersebut membentuk opini publik tentang sekolah favorit dan non favorit. Peserta didik yang memiliki kualitas mumpuni baik secara kognitif maupun secara finansial, lebih memilih sekolah di sekolah yang dianggap favorit walaupun sekolah tersebut jaraknya jauh dari tempat tinggal. Akibatnya sekolah yang dianggap non favorit diisi oleh siswa dengan kualitas yang pas-pasan baik secara kognitif maupun secara finansial dan mengalami kekurangan peserta didik. ${ }^{3}$

Permendikbud No. 44 Tahun 2019 menjelaskan bahwa penerimaan siswa melalui jalur zonasi paling sedikit 50\% dari daya tampung sekolah. Domisili berdasarkan alamat pada kartu keluarga yang diterbitkan paling singkat 1 tahun sebelum pelaksanaan PPDB. Kartu keluarga dapat diganti dengan surat keterangan domisili dari RT atau RW yang dilegalisir kepala desa setempat yang menerangkan bahwa peserta didik yang bersangkutan telah berdomisili paling singkat 1 tahun sejak diterbitkannya surat keterangan domisili. Jalur afirmasi paling sedikit 15\% dari daya tampung sekolah. Jalur perpindahan tugas orang tua/wali paling banyak $5 \%$ dari daya tampung sekolah, dan jika dari ketiga kuota tersebut masih sisa, maka pemerintah daerah dapat membuka jalur prestasi. ${ }^{4}$

Sistem zonasi dinilai banyak kelebihan yaitu dapat menghemat waktu, menghemat biaya transportasi karena sekolah dekat dengan tempat tinggal, serta mengurangi kemacetan. Adanya sistem zonasi ini diharapkan semua warga bisa mendapatkan pendidikan yang lokasinya dekat dengan tempat tinggal, pemerataan pendidikan di Indonesia serta menghilangkan anggapan masyarakat mengenai sekolah yang berlabel favorit. ${ }^{5}$

Di Kabupaten Jepara khususnya di kecamatan Mlonggo sebagian besar lulusan SD/MI mau tidak mau harus mengenyam pendidikan di sekolah yang berstatus swasta, dikarenakan jarak tempuh menuju sekolah negeri jauh. Jumlah SD dan MI di Kecamatan Mlonggo sendiri berjumlah 51 sekolah, sedangkan Jumlah SMP dan MTs sebanyak 12 sekolah, dan yang berstatus negeri

\footnotetext{
${ }^{1}$ Syafril dan Zelhendri Zen, Dasar-Dasar IImu Pendidikan(Depok: Kencana, 2017). hlm. 42

2 "Undang-Undang No.20 Tahun 2003," Sistem Pendidikan Nasional, n.d. Pasal 3

${ }^{3}$ M Arfan Mu' ammar, Nalar Kritis Pendidikan (Yogyakarta: Ircisos, 2019),
}

https://books.google.com/books?hl=en\&lr=\&id=0IjADwAAQBAJ\&oi=fnd\&pg=PA49\&dq=terorisme+presepsi+stigma+simbol+islam\&ot s=hGWogFIccK\&sig=wMZ9v2jHfmjYQ-f8jmoLL3DJs3g. hlm. 102

4 "Peraturan Menteri Pendidikan dan Kebudayaan Nomor 44 Tahun 2019," PPDB pada TK, SD, SMP, SMA dan SMK atau Bentuk Lain yang Sederajat, n.d. Pasal 16 ayat 1-5.

${ }^{5}$ Dian Purwanti et al., "Implementasi Kebijakan Penerimaan Peserta Didik Baru Berdasarkan Sistem Zonasi Di Kota di Kota Bandung," Jurnal Governansi 5, no. 1 (2019): 13. 
hanya 1 sekolah saja, selebihnya masih berstatus swasta. ${ }^{6}$ Realita di lapangan menunjukkan bahwa hampir sebagian lulusan SD/MI bersaing ketat untuk bisa masuk ke SMP Negeri 1 Mlonggo Jepara. Hal ini dikarenakan PPDB model zonasi sudah mampu diakses secara online, dikelola oleh tim IT Profesional dan calon wali murid berkeyakinan bahwa SMP Negeri 1 Mlonggo Jepara merupakan sekolah yang berkualitas.

SMP Negeri 1 Mlonggo Jepara dari tahun ketahun selalu menjadi incaran calon peserta didik baik calon peserta didik dari sekitar SMP maupun dari luar daerah SMP yang letak rumahnya jauh dari SMP. SMP Negeri 1 Mlonggo mempunyai banyak kelebihan, selain sarana prasarananya memadai, letak yang strategis, mudah dijangkau oleh transportasi umum, ia juga sebagai satusatunya sekolah menengah yang berstatus negeri di Kecamatan Mlonggo Jepara.

\section{METODE PENELITIAN}

Penelitian ini menggunakan pendekatan penelitian kualitatif. Penelitian ini digunakan untuk mendeskripsikan mengenai segala sesuatu yang berkaitan dengan pengelolaan PPDB berdasarkan sistem zonasi di SMP N 1 Mlonggo Jepara. Tempat penelitian ini berada di Jl. JeparaBangsri KM.7 Desa Suwawal RT 01/RW 01, Kecamatan Mlonggo, Kabupaten Jepara. Penelitian ini dilaksanakan pada tanggal 10 Agustus 2020. Adapun sumber data dalam penelitian ini dibagi menjadi dua yaitu sumber data primer dan sumber data sekunder. Data primer yang dimaksud adalah kepala sekolah dan panitia PPDB SMP N 1 Mlonggo Jepara sedangkan data sekunder yang dimaksud adalah peserta didik baru SMP N 1 Mlonggo Jepara. Fokus penelitian ini adalah pengelolaan (perencanaan, pengorganisasian, pelaksanaan, dan pengawasan) PPDB berdasarkan sistem zonasi di SMP Negeri 1 Mlonggo Jepara. Tekhnik pengumpulan data berupa wawancara, observasi, dokumentasi. Peneliti menggunakan teknik triangulasi sumber yang berarti membandingkan kembali tingkat keakuratan data dan informasi yang telah didapat dari berbagai sumber yang berbeda-beda. ${ }^{7}$ Tekhnik analisis data dalam penelitian ini menggunakan teori Matthew B. Milles dan A. Michael Hubarman terdiri dari tiga arus kegiatan yang bersamaan yaitu, data reduction, data display, dan conclusion drawing/verification. ${ }^{8}$

\section{HASIL PENELITIAN DAN PEMBAHASAN}

Menurut George R. Terry pengelolaan merupakan proses yang khas, yang terdiri dari tindakan-tindakan: perencanaan, pengorganisasian, menggerakkan, dan pengawasan, yang dilakukan untuk menentukan serta mencapai sasaran-sasaran yang telah ditetapkan melalui pemanfaatan sumber daya manusia serta sumber-sumber lain. ${ }^{9}$

Penerimaan peserta didik adalah suatu proses pencarian atau penarikan calon peserta didik yang mempunyai potensi dan kualitas untuk dijadikan input sekolah melalui proses seleksi yang sudah dirancang oleh sekolah. ${ }^{10}$ Prosedur PPDB meliputi:

${ }^{6}$ Budi Erje, "Dampak Zonasi, Banyak Calon Siswa SMP di Mlonggo Terpaksa Sekolah di Swasta," 25 Juni 2019, https://www.murianews.com/2019/06/25/166902/dampak-zonasi-banyak-calon-siswa-smp-di-mlonggo-terpaksa-sekolah-diswasta.html.

${ }^{7}$ Firdaus Fakhry Zamzam, Aplikasi Metodologi Penelitian, Aplikasi Metodologi Penelitian(Yogyakarta: Deepublish, 2018). hlm.110

${ }^{8}$ Matthew B Miles dan A Michael Huberman, An Expanded Sourcebook Qualitative Data Analysis, 2 ed. (London: Sage Publications, 1994). hlm.10

${ }^{9}$ Saifuddin, Pengelolaan Pembelajaran Teoritis dan Praktis (Yogyakarta: Deepublish, 2014). hlm.53-54

${ }^{10}$ Siti Maryam, "Pengelolaan Penerimaan Peserta Didik Baru (PPDB) di SMP Adzkia Islamic School" (UIN Syarif Hidayatullah, 2016). hlm. 14 


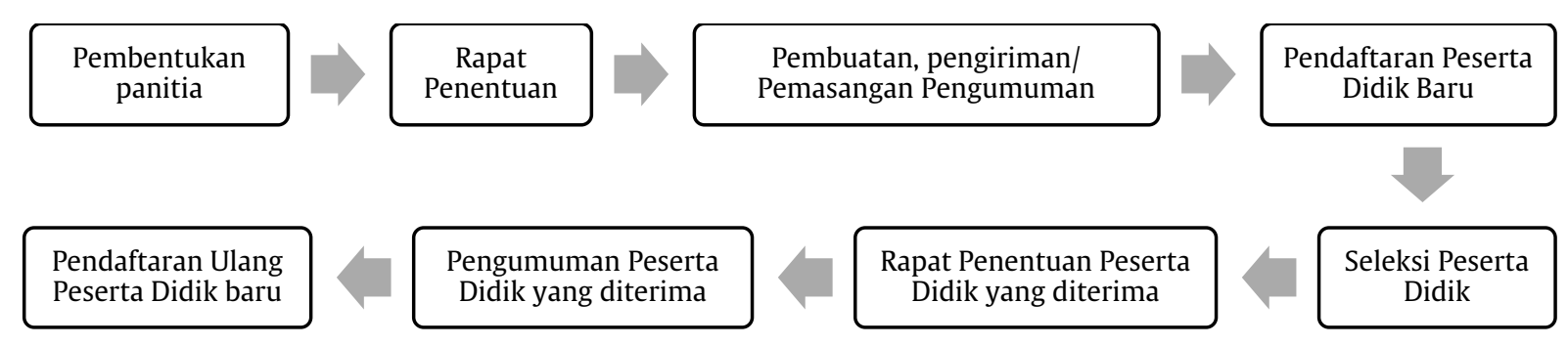

Gambar 1. Urutan Prosedur PPDB ${ }^{11}$

\section{Perencanaan}

Perencanaan adalah penentuan serangkaian tindakan untuk mencapai suatu hasil yang diinginkan. Rebecca J. Cropper mengatakan: "Planning is the basis from which all other function are spawned. Without a congruent plan, organization usually lack a central focus. Perencanaan adalah dasar dari mana semua fungsi lainnya dihasilkan. Tanpa perencanaan yang kongruen, organisasi biasanya tidak memiliki fokus sentral". ${ }^{12}$

Perencanaan PPDB secara umum dilaksanakan sesuai dengan juknis PPDB yang terdapat pada Surat Keputusan Kepala Dinas Pendidikan Pemuda dan Olah Raga Kabupaten Jepara Nomor 420/148.1 Tahun 2020, tentang Petunjuk Teknis Pelaksanaan Penerimaan Peserta Didik Baru Jenjang SMP Tahun Pelajaran 2020/2021, Surat Edaran Mendikbud SE 4 Tahun 2020 tentang Pelaksanaan Kebijakan Pendidikan dalam Masa Darurat Penyebaran Coronavirus Disease (COVID19), dan Permendikbud No. 44 tahun 2019 tentang PPDB pada TK, SD, SMP, SMA, dan SMK atau bentuk lain yang sederajat.

Hal utama dalam perencanaan PPDB yaitu pembentukan panitia PPDB yang dibentuk oleh kepala sekolah selaku penanggung jawab PPDB. Dalam perencanaan PPDB, kepala sekolah menyiapakan segala sesuatu yang sebelumnya dimusyawarahkan terlebih dahulu bersama panitia PPDB. Pada rapat pertama yaitu rapat secara umum yang diikuti oleh semua pendidik dan tenaga pendidik guna mensosialisasikan prosedur PPDB, agar semua pendidik dan tenaga pendidik ikut andil dalam memberikan informasi PPDB kepada masyarakat. Banyak hal yang dipersiapkan dalam PPDB, mulai dari petunjuk teknis, daya tampung, tempat, administrasi, penetapan anggaran, informasi pengumuman PPDB seperti pembuatan banner, brosur, dll. Perencanaan yang dilakukan SMP Negeri 1 Mlonggo selaras dengan pendapat Anang Firmansyah dan Budi W. Mahardika yang mengatakan jika perencanaan tidak

hanya menetapkan hal seperti tindakan apa yang harus dikerjakan, apakah sebabnya tindakan itu harus dikerjakan, dimana tindakan itu harus dikerjakan, kapankah tindakan itu dilaksanakan, siapakah yang akan mengerjakan tindakan itu dan, bagaimanakah caranya melaksanakan tindakan itu, tetapi dalam perencanaan penetapan biaya ( $b u d g e t)$ sudah termasuk didalamnya. ${ }^{13}$

Penyebaran informasi tentang penerimaan peserta didik baru di sekolah/madrasah dengan menggunakan berbagai macam media, meliputi:

Tabel 1.

Penyebaran Informasi PPDB

\begin{tabular}{llll}
\hline No & Media yang Digunakan & Waktu Pelaksanaan & Penanggung Jawab \\
\hline 1. & Brosur & Minggu ke 1 bulan Juni & Agus Purwanto, SE \\
2. & Surat Edaran & Minggu ke 1 bulan Juni & Hanifa Krisnawati \\
3. & Papan Pengumuman & Minggu ke 2 bulan Juni & Agus Purwanto, SE \\
4. & Banner & Minggu ke 2 bulan Juni & Agus Purwanto, SE \\
5. & Web SMP Negeri 1 Mlonggo & Minggu ke 1 bulan Juni & Hanifa Krisnawati \\
\hline
\end{tabular}

\footnotetext{
${ }^{11}$ Muhammad Kristiawan dan Jimmi Yuliandri, Manajemen Pendidikan (Yogyakarta: Deepublish, 2017). hlm.72

${ }^{12}$ Cropper, Rebecca J., "A Management Approach to Country Extension Progams," Journal Of Extension 36, No. 6 (1998).

${ }^{13}$ Anang Firmansyah dan Budi W. Mahardika, Pengantar Manajemen(Yogyakarta: Deepublish, 2018). hlm. 11
} 
Selain menyebarkan informasi dengan berbagai media di atas, sekolah juga melakukan kerjasama dengan majalah bumi kartini yang diterbitkan setiap minggu pertama di bulan Juni.

\section{Pengorganisasian}

Menurut Anang Firmansyah dan Budi W. Mahardika pengorganisasian adalah keseluruhan kegiatan manajemen dalam mengelompokkan orang-orang serta penetapan tugas, fungsi, wewenang, serta tanggung jawab masing-masing dengan tujuan terciptanya aktivitas-aktivitas yang berdaya guna dan berhasil guna dalam mencapai tujuan yang telah ditentukan. ${ }^{14}$ Kepala sekolah membentuk panitia PPDB serta menetapkan tugas-tugsanya setelah menghadiri rapat dinas, dan dikarenakan pendaftaran PPDB dilakukan secara online maka pembentukan panitia PPDB kepala sekolah mengutamakan pendidik dan tenaga pendidik yang menguasai ICT (Information and Communication Technology) agar perencanaan dapat dilaksanakan secara efektif dan efisien dan sekolah dapat memberikan pelayanan yang baik kepada masyarakat. Pengorganisasian atau penetapan tugas panitia PPDB: 1) Penanggung jawab: bertanggung jawab secara keseluruhan terhadap pelaksanaan penerimaan peserta didik baru, 2) Ketua Pelaksana: mengkoordinir semua kegiatan PPDB, memonitor pelaksanaan kegiatan PPDB, membuat dan melaksanakan aturan teknis kegiatan PPDB, dan bertanggungjawab kepada penanggungjawab kegiatan PPDB, 3) Sekretaris: menyiapkan semua administrasi kegiatan PPDB, menyusun jurnal sementara PPDB, membuat pengumuman resmi PPDB dan membantu ketua menyusun laporan Pelaksanaan PPDB, 4) Bendahara: mengelola keuangan selama pelaksanaan PPDB, menyusun SPJ pelaksanaan PPDB, 5) Seksi-seksi:a) seksi kesekretariatan: menginput data pendaftar pada situs PPDB, b) seksi sosialisasi/publikasi: membuat brosur untuk sosialisasi pendaftaran, membuat pengumuman syarat-syarat pendaftaran, mendokumentasikan pelaksanaan PPDB, c) seksi pendaftaran: mengecek kelengkapan berkas pendaftar, menuliskan biodata pendaftar ke dalam buku induk, d) seksi seleksi: memilah berkas pendaftar yang diterima dan tidak diterima, melayani pencabutan berkas bagi pendaftar yang tidak diterima, mengkoordinir tes seleksi kelas unggulan bagi peserta didik baru yang diterima, e) seksi monitoring dan evaluasi: memantau dan mengevaluasi pelaksanaan PPDB, f) seksi keamanan: menjaga keamanan secara keseluruhan selama pelaksanaan PPDB

\section{Pelaksanaan}

Pelaksanaan adalah rangkaian kegiatan yang dilakukan setelah dirumuskan perencanaan dan pengorganisasian. Pelaksanaan dilakukan ketika perencanaan telah dirumuskan, termasuk anggaran biaya yang diperlukan atau yang diharapkan, struktur organisasi, dan tim kerja serta kebutuhan untuk menunjang pelaksanaan sudah siap.

Pelaksanaan PPDB berdasarkan sistem zonasi mengusung 5 prinsip, yaitu: 1) Non diskriminatif artinya semua warga negara yang berusia sekolah berhak mengikuti program pendidikan di Indonesia tanpa membedakan suku, daerah, agama, dan golongan. Prinsip ini dikecualikan bagi sekolah yang secara khusus melayani peserta didiki dari kelompok gender atau agama tertentu, 2) Objektif artinya pelaksanaan PPDB harus dilaksanakan sesuai ketentuan dari pemerintah, 3) Transparan, pelaksanaan PPDB bersifat terbuka, dapat diketahui oleh masyarakat, termasuk orang tua/wali dan calon peserta didik, 4) Akuntabel berarti PPDB dapat dipertanggung jawabkan kepada pemerintah maupun masyarakat baik prosedur maupun hasilnya. ${ }^{15}$ ) Berkeadilan artinya pelaksanaan PPDB harus mengutamakan keadilan

Ketentuan sistem zonasi tertera dalam Permendikbud No. 44 tahun 2019, yang dijelakan bahwa dalam pendaftaran PPDB dilaksanakan melalui jalur berikut: 1) Jalur zonasi paling sedikit $50 \%$ daya tampung sekolah. Domisili tersebut berdasarkan alamat pada kartu keluarga atau bisa

\footnotetext{
${ }^{14}$ Firmansyah dan W. Mahardika. hlm. 11

${ }^{15}$ Ali Muhammad, Kebijakan Pendidikan Menengah dalam Perspektif Governance di Indonesia(Malang: UB Press, 2017). hlm. 143-144
} 
diganti dengan surat keterangan domisili dari RT/RW yang dilegalisir oleh lurah/kepala desa atau pejabat setempat lain yang berwenang menerangkan bahwa peserta didik yang bersangkutan telah berdomisili paling singkat 1 tahun sejak diterbitkannya surat keterangan domisili, 2) Jalur afirmasi paling sedikit 15\% dari daya tampung sekolah. Jalur afirmasi diperuntukkan bagi peserta didik domisili dalam dan luar wilayah zonasi sekolah yang berasal dari keluarga ekonomi tidak mampu yang dibuktikan dengan keikutsertaan peserta didik dalam program penanganan keluarga tidak mampu dari pemerintah pusat atau pemerintah daerah, 3) Jalur perpindahan tugas orang tua/wali paling banyak 5\% dari daya tampung sekolah yang dibuktikan dengan surat penugasan dari instansi, lembaga, kantor, atau perusahaan yang memperkerjakan, 4) Jika dari keempat jalur diatas masih terdapat sisa kuota maka pemerintah daerah dapat membuka jalur prestasi yang ditentukan berdasarkan: a) Nilai ujian sekolah atau UN, b) Hasil perlombaan atau penghargaan di bidang akademik maupun non akademik pada tingkat internasional, nasional, provinsi, atau tingkat kabupaten/kota yang diterbitkan paling singkat 6 bulan dan paling lama 3 tahun sejak tanggal pendaftaran PPDB.

Ketentuan mengenai jalur pendaftaran PPDB diatas dikecualikan bagi sekolah berikut: 1) Sekolah yang diselenggarakan oleh masyarakat, 2) SMK yang diselenggarakan oleh pemerintah daerah, 3) Sekolah kerja sama, 4) Sekolah Indonesia di luar negeri, 5) Sekolah yang menyelenggarakan pendidikan khusus, 6) Sekolah yang menyelenggarakan pendidikan layanan khusus, 7) Sekolah berasrama, 8) Sekolah di daerah tertinggal, terdepan, dan terluar, 9) Sekolah di daerah yang jumlah penduduk usia sekolah tidak dapat memenuhi ketentuan jumlah peserta didik dalam satu rombongan belajar.

Pelaksanaan pendaftaran peserta didik baru dilaksanakan secara online melalui website www.jepara.siap-ppdb.com. Adanya pandemi covid-19 mengharuskan pendaftaran dilakukan secara online mandiri. Namun pada kenyataanya masih banyak masyarakat yang kurang paham akan tata cara pendaftaran sehingga, sekolah membantu pendaftaran peserta didik sesuai protokol covid-19 dengan menyediakan 3 ruang kelas untuk membantu siswa yang menunggu proses verifikasi dan aula outdor untuk membantu siswa yang belum sama sekali melakukan pendaftaran.

Tata cara pendaftaran calon peserta didik baru yaitu: 1) Calon peserta didik melakukan pendaftaran secara online pada alamat website www.jepara.siap-ppdb.com, 2) Mengunggah (upload) kelengkapan pendaftaran terdiri dari; a) Surat kelulusan dari sekolah/Madrasah/Kejar paket, b) KK dan KTP orang tua/wali, c) Salah satu bukti prestasi jenjang tertinggi bidang akademik/olahraga/kesenian/keterampilan atau dalam bidang lainnya dalam kurun waktu tahun 2018 s/d 2020, d) Surat keterangan miskin dari dinas/instansi yang berwenang, e) KIP bagi yang memiliki, f) Surat perpindahan tugas orang tua calon peserta didik dari dinas/instansi/lembaga tempat orang tua bekerja (apabila ada); 3) Mencetak tanda bukti pendaftaran, 4) Menyerahkan tanda bukti pendaftaran ke sekolah yang dituju untuk diverifikasi petugas PPDB, 5) Melihat jurnal harian dan pengumuman hasil PPDB online setiap hari yang dapat diakses melalui internet maupun handphone. Atau dapat datang melihat pengumuman ke sekolah yang bersangkutan sesuai dengan protokol penanggulangan covid-19, 6) Proses pencabutan pendaftaran bagi siswa yang masih diterima pada jurnal seleksi dan ingin pindah sekolah akan diproses oleh panitia PPDB kabupaten paling lambat sehari sebelum tanggal penutupan 10 Juni 2020 pukul 13.00 maksimal 2 kali.

Alur pendaftaran calon peserta didik baru yaitu adanya kebijakan sistem zonasi proses seleksi peserta didik baru dilakukan oleh sistem pendaftaran online secara otomatis berdasarkan ketentuan kebijakan dari pemerintah. Pihak sekolah tidak ikut andil dalam tahapan ini. Langkah pertama pendaftaran PPDB yaitu siswa mengajukan akun, kemudian memilih jalur PPDB dan memilih 2 pilihan sekolah. Jika jalur pertama yang dipilih tidak sesuai dengan sekolah pilihan 1 , maka otomatis pindah ke sekolah pilihan 2. Jika sekolah pilihan 2 tidak diterima juga, maka lanjut seleksi menggunakan jalur pilihan kedua. Berikut ini gambar 2, 3, 4, dan 5 adalah hasil seleksi pendaftaran peserta didik baru: 


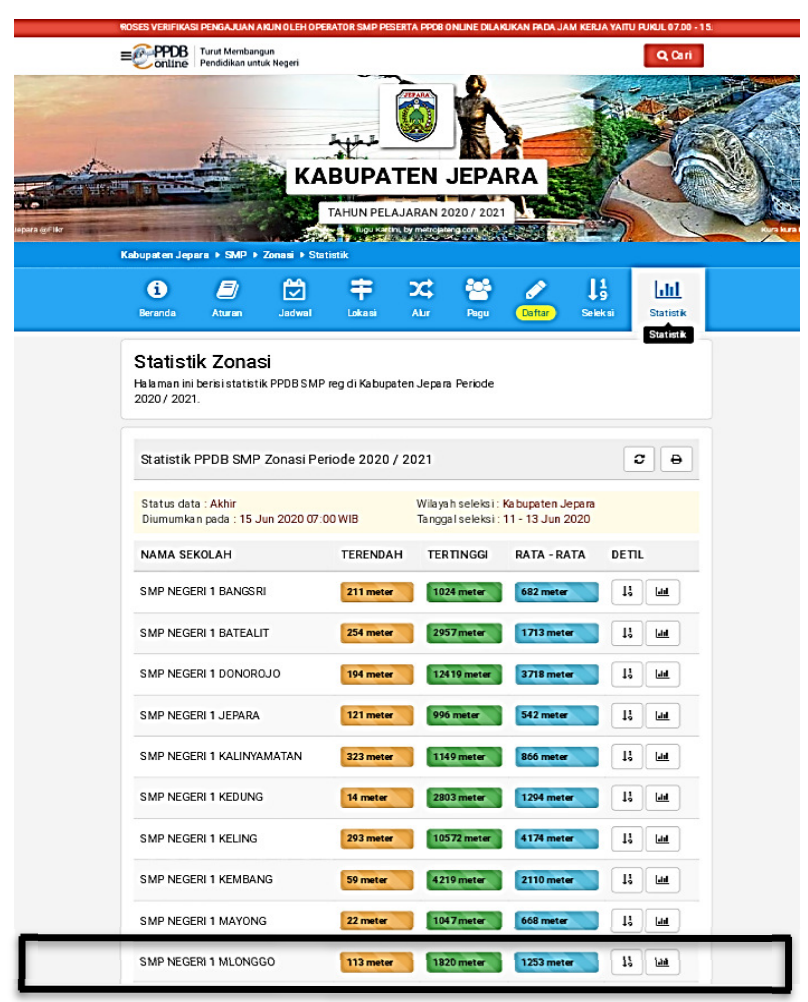

Gambar 2.

Website PPDB Jalur Zonasi

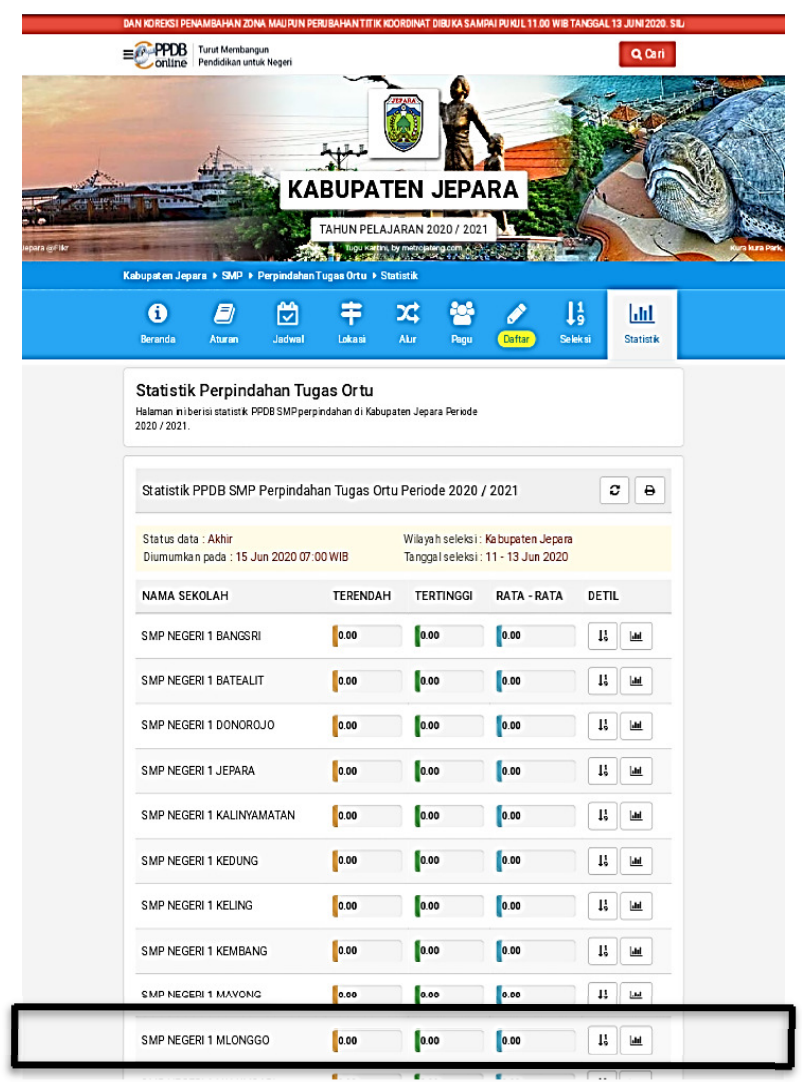

Gambar 4.

Website PPDB Jalur Perpindahan Tugas Orang tua

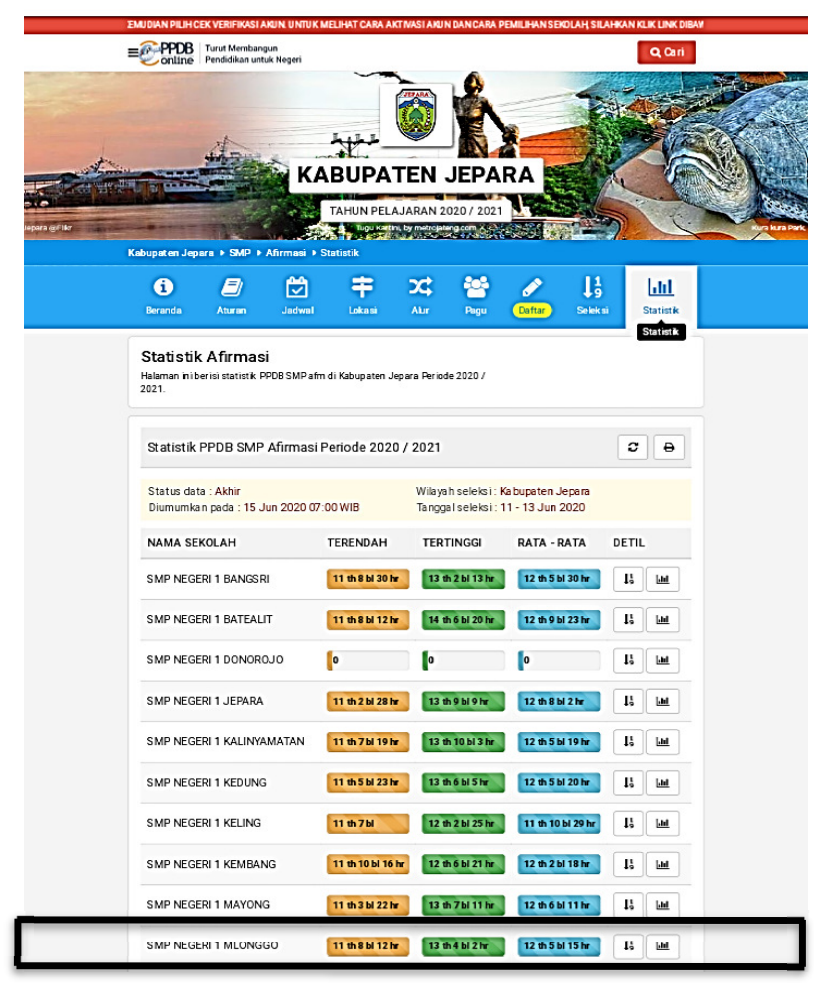

Gambar 3.

Website PPDB Jalur Afirmasi

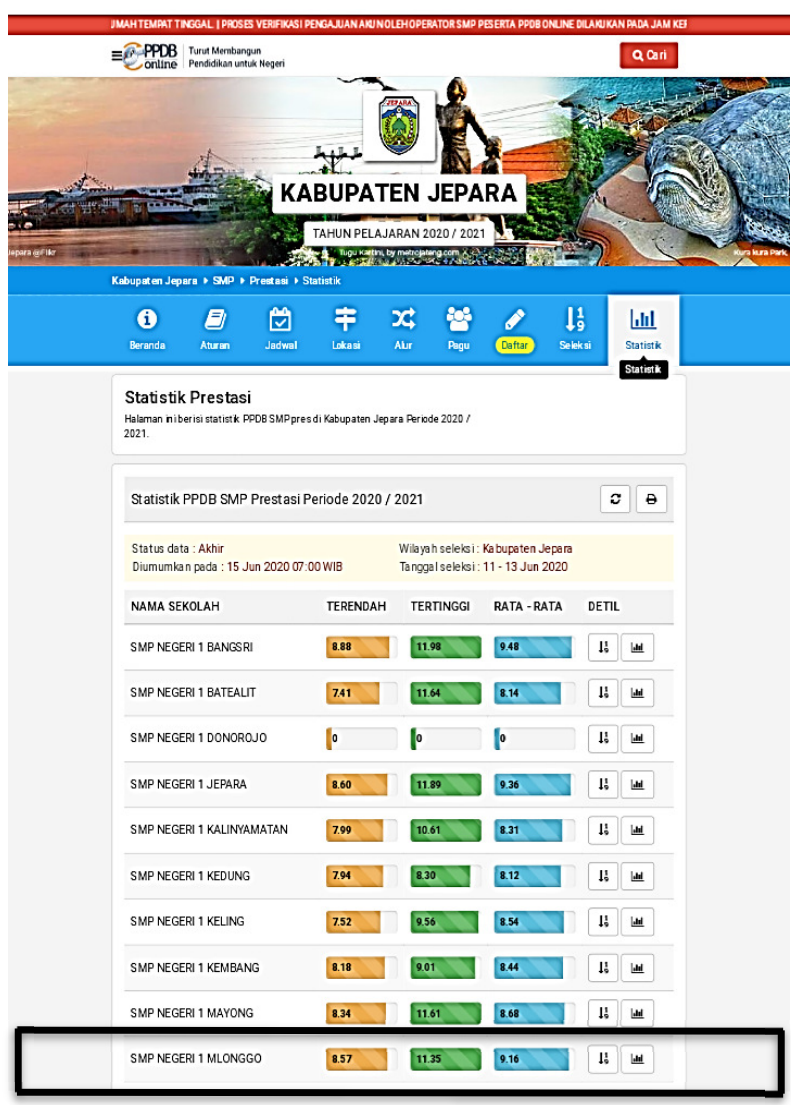

Gambar 5.

Website PPDB Jalur Prestasi 


\section{Jalur Zonasi}

Berdasarkan data Gambar 2 di atas dari website https://jepara.siap-ppdb.com, dapat dijelaskan bahwa hasil dari seleksi pada jalur zonasi jarak terdekat tempat tinggal peserta didik baru yang diterima yaitu 113 meter dari sekolah, jarak terjauh tempat tinggal peserta didik baru yang diterima yaitu 1820 meter dari sekolah, dan rata-rata 1253 meter dari sekolah. Seleksi jalur zonasi berdasarkan jarak tempuh tempat tinggal calon peserta didik dari sekolah yang dituju.

\section{Jalur Afirmasi}

Berdasarkan data Gambar 3 di atas dapat dijelaskan bahwa hasil dari seleksi pada jalur afirmasi umur terendah peserta didik baru yang diterima yaitu 11 tahun 8 bulan 12 hari, umur tertinggi peserta didik baru yang diterima 13 tahun 4 bulan 2 hari, dengan rata-rata umur peserta didik baru yaitu 12 tahun 5 bulan 15 hari.

\section{Jalur Perpindahan Tugas Orang tua/Wali}

Berdasarkan data Gambar 4 di atas, hasil seleksi pada jalur perpindahan tugas orang tua atau wali menunjukkan angka 0 , artinya tidak ada siswa yang mendaftar melalui jalur ini, maka kuota pada jalur ini ditambahkan ke kuota jalur zonasi.

\section{Jalur Prestasi}

Berdasarkan data Gambar 5 di atas, Hasil seleksi pada jalur prestasi menunjukkan nilai akhir terendah yaitu 8,57, nilai akhir tertinggi 11, 35 dan rata-rata 9,16. Adapun pedoman jalur prestasi ditunjukkan pada tabel 2 berikut,

Tabel 2.

Pedoman Jalur Prestasi

\begin{tabular}{llllll}
\hline No & Event/jenjang & Peringkat & Jumlah Bonus Nilai Untuk Peserta Didik & Dari Luar Provinsi \\
\cline { 4 - 6 } . & & & Dalam wilayah kab/kota & Dari Luar Kab/Kota dalam Provinsi & Langsung diterima \\
\hline 1. & Internasional & I, II, III & Langsung diterima & Langsung diterima & Langsung diterima \\
2. & Nasional & I, II, III & Langsung diterima & Langsung diterima & 3,0 \\
3. & Provinsi & I & Langsung diterima & 3,5 & 2,5 \\
& & II & Langsung diterima & 3,0 & 2,0 \\
& & III & Langsung diterima & 2,5 & 1,5 \\
4. & Kab/Kota & I & Langsung diterima & 2,0 & 1.0 \\
& & II & 2,5 & 1,5 & 0,5 \\
\hline
\end{tabular}

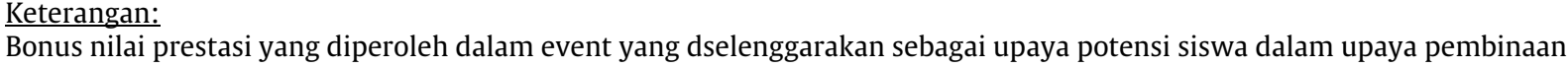
kesiswaan yang linier dengan kegiatan yang diselenggarakan oleh:

1. Kementrian Pendidikan dan Kebudayaan

2. Dinas Pendidikan Provinsi

3. Dinas Pendidikan/Kementrian Agama Kabupaten/Kota

4. Lembaga/Instansi lain yang menerapkan standar penilaian baku dan dalam penyelenggaraanya terstruktur dan berjenjang

Berdasarkan sistem zonasi yang pendaftarannya dilakukan secara online, tidak ada tahapan rapat penetapan peserta didik yang akan diterima, karena proses seleksi dilakukan otomatis oleh sistem pendaftaran. Berikut prosedur PPDB SMP Negeri 1 Mlonggo Jepara: 


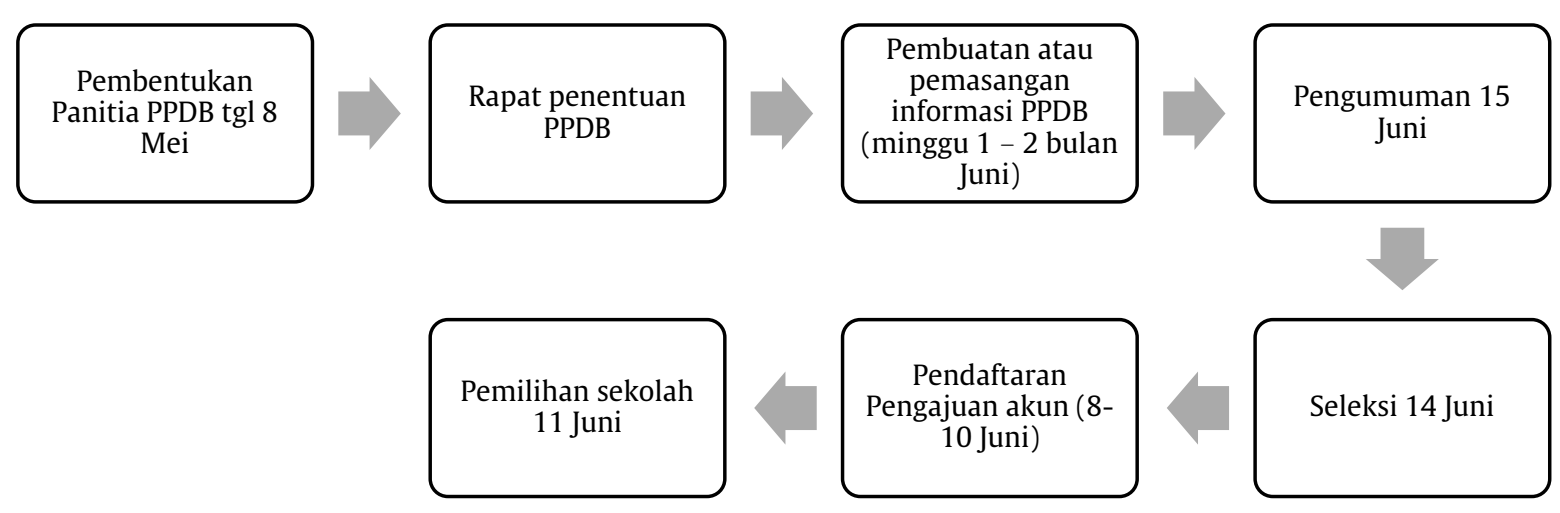

Gambar 6.

Alur PPDB SMP Negeri 1 Mlonggo Jepara

\section{Pengawasan}

Berdasarkan pendapat Hadari Nawawi pengawasan atau kontrol adalah proses mengukur (measurement) dan menilai (evaluation) tingkat efektivitas kerja anggota dan tingkat efisiensi penggunaan sarana kerja pencapaian tujuan organisasi. ${ }^{1}$ Kegiatan pengawasan dilakukan kepala sekolah selaku penanggung jawab PPDB dengan mengadakan rapat evaluasi setiap akhir jam pelayananan PPDB. Rapat ini diadakan selama proses pendaftaran peserta didik baru. Rapat evaluasi diadakan guna mengetahui dan menilai apakah pelaksanaan pendaftaran peserta didik baru sudah sesuai dengan juknis, apakah terdapat kekurangan atau kesalahan. Jika terdapat kekurangan maka dapat diperbaiki secepatnya dan pendaftaran peserta didik baru esok harinya maupun tahun ajaran berikutnya dapat berjalan semakin baik. Kepala sekolah juga mengadakan rapat sebelum pembuatan jurnal atau laporan PPDB.

\section{SIMPULAN}

Perencanaan kegiatan PPDB dilakukan sesuai juknis dari pemerintah. Hal utama dari perencanaan PPDB yaitu membentuk team work atau panitia PPDB dan menyusun struktur organisasi serta penetapan tugasnya sehingga setiap panitia dapat fokus bekerja sesuai dengan tugas masing-masing. Pendaftaran peserta didik dilakukan secara online, maka dari itu pembentukan panitia PPDB dipilih berdasarkan karyawan atau pegawai yang menguasai ICT (Information and Communication Technology)

Pelaksanaan pendaftaran dilakukan secara online mandiri melalui website www.jepara.siap-ppdb.com. Sekolah tetap siap sedia membantu masyarakat melakukan pendaftaran sesuai dengan protokol covid-19. Proses seleksi secara otomatis dilakukan oleh sistem, dan pengumuman peserta didik yang lolos seleksi diumumkan di website pendaftaran. Sekolah juga ikut andil dalam pengumuman peserta didik yang lolos seleksi dengan menempelkan pengumuman di pintu gerbang sekolah, sehingga semua masyarakat dapat melihat informasi kapanpun dengan datang ke sekolah. Tahap rapat penentuan peserta didik yang diterima dalam prosedur PPDB tidak berlaku pada PPDB berdasarkan sistem zonasi.

Pengawasan kegiatan PPDB dilakukan kepala sekolah selaku penanggung jawab PPDB, diantaranya dengan mengadakan rapat evaluasi setiap akhir jam pelayananan PPDB yang diadakan selama proses pendaftaran peserta didik baru, rapat sebelum pembuatan jurnal atau laporan PPDB.

${ }^{1}$ Sri Marmoah, Manajemen Pemberdayaan Perempuan Rimba (Yogyakarta: Deepublish, 2014). hlm. 41 


\section{DAFTAR PUSTAKA}

Cropper, Rebecca J. "A Management Approach to Country Extension Progams." Journal Of Extension 36, no. 6 (1998).

Erje, Budi. "Dampak Zonasi, Banyak Calon Siswa SMP di Mlonggo Terpaksa Sekolah di Swasta." 25 Juni 2019. https://www.murianews.com/2019/06/25/166902/dampak-zonasi-banyakcalon-siswa-smp-di-mlonggo-terpaksa-sekolah-di-swasta.html.

Firmansyah, Anang, dan Budi W. Mahardika. Pengantar Manajemen. Yogyakarta: Deepublish, 2018.

Kristiawan, Muhammad, dan Jimmi Yuliandri. Manajemen Pendidikan. Yogyakarta: Deepublish, 2017.

Marmoah, Sri. Manajemen Pemberdayaan Perempuan Rimba. Yogyakarta: Deepublish, 2014.

Maryam, Siti. "Pengelolaan Penerimaan Peserta Didik Baru (PPDB) di SMP Adzkia Islamic School." UIN Syarif Hidayatullah, 2016.

Miles, Matthew B, dan A Michael Huberman. An Expanded Sourcebook Qualitative Data Analysis. 2 ed. London: Sage Publications, 1994.

Mu' ammar, M Arfan. Nalar Kritis Pendidikan. Yogyakarta: Ircisos, 2019. https://books.google.com/books?hl=en\&lr=\&id=0IjADwAAQBAJ\&oi=fnd\&pg=PA49\&dq=te rorisme+presepsi+stigma+simbol+islam\&ots=hGWogFIccK\&sig=wMZ9v2jHfmjYQf8jmoLL3DJs3g.

Muhammad, Ali. Kebijakan Pendidikan Menengah dalam Perspektif Governance di Indonesia. Malang: UB Press, 2017.

"Peraturan Menteri Pendidikan dan Kebudayaan Nomor 44 Tahun 2019." PPDB pada TK, SD, SMP, SMA dan SMK atau Bentuk Lain yang Sederajat, n.d.

Purwanti, Dian, Ira Irawati, Jossi Adiwisastra, dan Herijanto Bekti. "Implementasi Kebijakan Penerimaan Peserta Didik Baru Berdasarkan Sistem Zonasi Di Kota di Kota Bandung." Jurnal Governansi 5, no. 1 (2019): 13.

Saifuddin. Pengelolaan Pembelajaran Teoritis dan Praktis. Yogyakarta: Deepublish, 2014.

Syafril, dan Zelhendri Zen. Dasar-Dasar IImu Pendidikan. Depok: Kencana, 2017.

Undang-Undang No. 20 Tahun 2003. Sistem Pendidikan Nasional, n.d.

Zamzam, Firdaus Fakhry. Aplikasi Metodologi Penelitian. Aplikasi Metodologi Penelitian. Yogyakarta: Deepublish, 2018. 